\title{
Kết quả ban đầu của đánh giá tác động Chi trả Dịch vụ Môi trường Rừng (PFES) đối với mạng lưới rừng và quản trị, thu nhập hộ gia đình và thực trạng mất rừng ở Việt Nam
}

\author{
Phạm Thu Thủy', Matthew Hamilton² và Caleb Gallemore ${ }^{3}$
}

\section{Thông điệp chính}

- Số lượng lớn các hội thảo nâng cao năng lực về cơ chế chi trả dịch vụ môi trường rừng (PFES) do nhiều cơ quan trong và ngoài nước thực hiện trong nhiêu năm qua đã góp phần quan trọng trong việc thúc đẩy hợp tác giưa các bên có liên quan, từ đó nâng cao hiệu quả hoạt động của những sáng kiến quản trị rừng. Tuy nhiên, nghiên cứu cho thấy có nhiều tổ chức tuy cùng làm việc về PFES trong một tỉnh nhưng lại không thường xuyên hợp tác với nhau.

- Tác động của PFES lên thu nhập của hộ dân tuỳ thuộc vào mức độ chi trả của PFES, các loại hình sinh kế của người dân trên địa bàn, diện tích rừng quản lý bởi các hộ gia đình, và loại hình hợp đông kí kết (ví dụ: giữa các hộ gia đình và quỹ hoặc giữa chính quyền thôn và cơ quan quản lý PFES)

- PFES đã thành công trong việc giảm tỉ lệ phá rừng ở những diện tích rừng đã bị phá từ năm 2000. Tác động của PFES đối với việc giảm phá rừng phụ thuộc vào thời gian thực hiện PFES tại các tỉnh. Thời gian thực hiện PFES càng dài, khả năng PFES giảm phá rừng càng lớn

- Kết quả về tác động PFES như thế nào phụ thuộc rất nhiều vào phương pháp đánh giá được sử dụng. Trong khi bản tóm tắt này thảo luận tác động của PFES đối với quản trị rừng, thu nhập của người dân địa phương và tỉ lệ mất rừng một cách tách biệt, đánh giá kết hợp sự tương tác qua lại của ba yếu tố này với nhau có thể sẽ chỉ ra bức tranh phức tạp hơn về tác động của PFES trong thực tế

\section{Giới thiệu}

Việt Nam là một trong số ít các quốc gia trên thế giới và là nước đầu tiên trong khu vực Châu Á có chương trình Quốc Gia về Chính sách Chi trả Dịch vụ Môi trường Rừng (PFES). Chương trình này được bắt đầu từ 2008 với mục tiêu chính là để tạo ra nguồn tái chính mới cho công tác quản lý và bảo vệ rừng ở Việt Nam nhằm cung cấp các dịch vụ môi trường bao gồm bảo vệ nguôn nước, vẻ đẹp cảnh quan, bảo tồn đa dạng sinh học và hấp thụ các-bon. PFES đóng vai trò quan trọng trong tài chính của ngành lâm nghiệp, chiếm đến 29\% tổng đầu tư vào ngành lâm nghiệp trong năm 2019. Những báo cáo trước đây của Chính phủ đã ghi

\footnotetext{
Tổ chức Nghiên cứu Lâm nghiệp Quốc tế (CIFOR)

2 Đại Học Ohio

Đại Học Lafayette
}

nhận những tác động tích cực của PFES đối với môi trường và kinh tế như là tăng độ che phủ rừng và đóng góp và thu nhập hộ gia đình. Tuy nhiên, cần có nhiều đánh giá toàn diện và mang tính khoa học về tác động của PFES, bởi nhiều đánh giá hiện nay một phần do thiếu sự áp dụng của những phương pháp khoa học đáng tin cậy một phần là do sự thiếu hụt về số liệu sẵn có nên đã đưa ra các kết quả thiếu chính xác. Để giải quyết những lỗ hổng kiến thức này, tóm lược chính sách này sẽ tổng hợp và phân tích một số kết quả ban đầu từ hai dự án, "Xác định các điều kiện để thực hiện thành công chính sách bảo tồn quy mô cảnh quan" được tài trợ bở USAID thông qua chương trình Quan hệ đối tác để nâng cao gắn kết trong nghiên cứu (PEER), và "Nghiên cứu so sánh toàn cầu về REDD+ (GCS-REDD)" do NORAD tài trợ nhằm đánh giá tác động của PFES đối với quản trị rừng, thu nhập hộ gia đình và giảm phá rừng ở Việt Nam. Báo cáo tóm tắt này là sự phối hợp hợp tác giữa CIFOR, Đại học bang Ohio và Cao đẳng Lafayette. 


\section{Tác động của PFES đối với mạng lưới rừng và quản trị}

Một trong những mục tiêu quan trọng của PFES là huy động nguồn lực của các nhóm xã hội (cơ quan nhà nước, các tổ chức phi chính phủ, cộng đồng, khối tư nhân và các viện nghiên cứu) đóng góp vào việc bảo vệ và phát triển rừng. Quản trị rừng hiệu quả cũng cần có sự hợp tác thường xuyên giữa các bên có liên quan trên cùng một cảnh quan. Ví dụ, các tổ chức có thể chia sẻ dữ liệu thông tin về hiệu quả thực hiện PFES, từ đó tạo điều kiện chia sẻ kinh nghiệm giữa nhiều bên tham gia thực hiện PFES. Việc học hỏi và phối hợp hợp tác giữa các bên cũng nâng cao hiệu quả và hiệu ích thực hiện của PFES. Các tổ chức cũng có thể phối hợp để thực hiện các chương trình bảo vệ rừng hoặc điều phối để giảm sự chồng chéo lãng phí tài nguyên trong việc thực hiện các dự án bảo tôn đa dạng hiện hành. Nghiên cứu trước đây cho thấy những sự kiện chia sẻ thông tin, nâng cao năng lực và đàm thoại về chính sách đã tạo điều kiện cho nhiều tổ chức biết đến nhau, xác định được những mối quan tâm chung hoặc khả năng bổ sung cho nhau, từ đó xây dựng các chương trình hợp tác lâu dài trong lĩnh vực này. Kể từ khi PFES được triển khai ở Việt Nam vào 2008, các nhà tài trợ quốc tế và các cơ quan chính phủ đã dành nguồn kinh phí đáng kể để tổ chức nhiều hội thảo và các chương trình đào tạo liên quan đến PFES. Tuy nhiên, những phân tích có hệ thống về tác động của những hội thảo này vẫn còn hạn chế, đặc biệt là hiệu quả của các sự kiện này đối với sự hợp tác giữa các bên có liên quan. Ngoài ra, nhiều nghiên cứu trước đây thường cho thấy các tổ chức cùng hoạt động trên một địa bàn hay làm việc về mặt địa lí gần nhau thì thường hợp tác với nhau chặt chẽ và thường xuyên hơn. Trong nghiên cứu này, chúng tôi tập trung nghiên cứu các yếu tố hỗ trợ sự hợp tác giữa các tổ chức có tham gia vào các hoạt động liên quan đến PFES. Chúng tôi đặc biệt chú ý đến vai trò của các sự kiện liên quan đến PFES (như các hội thảo tham vấn, các buổi tập huấn và đối thoại liên quan đến PFES), và cách thức mà những sự kiện này có thể tạo ra cơ hội cho các bên hợp tác thường xuyên và hiệu quả hơn. Chúng tôi cũng đánh giá liệu trong thực tế liệu khi thực hiện các hoạt động PFES trong cùng một tỉnh, có thực sự là các tổ chức hợp tác và phối hợp thường xuyên và hiệu quả ?

Để trả lời các câu hỏi nghiên cứu trên đây, chúng tôi đã dựa trên số liệu sẵn có về mạng lưới PFES tại Việt Nam, bao gồm:

Dũ liệu từ Nghiên cứu so sánh toàn câu của CIFOR về $R E D D+$. Dự án này được tài trợ bởi NORAD nhằm đánh giá tương tác mạng lưới giữa các tổ chức thực hiện
REDD + và PFES tại Việt Nam qua ba mốc thời gian (2011-2012, 2015-2016 và 2018-2019).

Dũ liệu về việc các hội thảo vê PFES và REDD+ đã được tổ chức bởi USAID, GIZ và CIFOR trong khuôn khổ hợp dưới sự hợp tác với Quỹ Bảo vệ và Phát triển Rừng Việt Nam từ năm 2008 cho tới nay. Mặc dù còn có nhiêu các tổ chức khác cũng đã tổ chức nhiều hội thảo có liên quan đến vấn đề này, tuy nhiên số liệu của họ không đầy đủ qua các năm do vậy chúng tôi chỉ phân tích những số liệu hiện có đầy đủ, hệ thống và cập nhật nhất do 4 cơ quan này lưu trữ.

Các thông tin công khai săn có (ví dụ từ các website của tổ chức), bao gồm những thông tin về địa bàn hoạt động của mỗi tổ chức và các hoạt động PFES và REDD+ mà họ thực hiện.

Chúng tôi kết hợp ba bộ dữ liệu vào một mạng lưới dọc (mang lưới qua thời gian) bao gồm ba loai đơn vị nghiên cứu khác nhau: số lượng tổ chức, số lượng hội thảo và số lượng địa bàn hoạt động (các tỉnh thành). Để có thể đánh giá được tác động và sự tương tác của 3 đơn vị nghiên cứu này tại các thời điểm khác nhau, chúng tôi xây dựng và áp dụng các mô hình phân tích tác nhân ngẫu nhiên (SAOM). SAOM là các mô hình thống kê đánh giá sự thay đổi về mô hình hợp tác giữa các bên theo thời gian (xem chi tiết tại Bảng 1).

\section{Bảng 1. Các yếu tố ảnh hưởng đến sự hợp tác giữa các tổ} chức

\begin{tabular}{|c|c|}
\hline Tham số & Ước tính (sai số chuẩn) \\
\hline Tî lệ tham số giai đoạn 1 & $7.39(0.49)^{* * *}$ \\
\hline Tî lệ tham số giai đoạn 2 & $5.58(0.45)^{* * *}$ \\
\hline $\begin{array}{l}\text { Liên kết hướng ngoại } \\
\text { (mật độ) }\end{array}$ & $-1.61(0.18)^{* * *}$ \\
\hline Tương tác qua lại & $-0.00(0.20)$ \\
\hline $\begin{array}{l}\text { Các tổ chức cùng tham gia } \\
\text { các hội thảo trong cùng } \\
\text { một thời điểm }\end{array}$ & $0.53(0.22)^{*}$ \\
\hline $\begin{array}{l}\text { Các tổ chức cùng làm việc } \\
\text { tại cùng tỉnh thành }\end{array}$ & $-0.31(0.15)^{*}$ \\
\hline Tổ chức chính phủ & $0.51(0.33)$ \\
\hline $\begin{array}{l}\text { Sự phối hợp giữa các tổ } \\
\text { chức chính phủ }\end{array}$ & $0.56(0.20)^{* * *}$ \\
\hline Phép lặp lại & 2669 \\
\hline
\end{tabular}

Ghi chú: *** $p<0.001 ;{ }^{* *} p<0.01 ;{ }^{*} p<0.05$

Nguồn: Phân tích của tác giả (2021) 
Kết quả nghiên cứu của chúng tôi chỉ ra hai phát hiện quan trọng:

\section{i. Khi các tổ chức cùng tham gia vào một hội thảo, họ} có xu hướng hợp tác trong tương lai. Hội thảo có rất nhiều chức năng. Ví dụ, người tham dự có thể tăng kiến thức chuyên môn hoặc tiếp cận thông tin mới. Kết quả của chúng tôi chỉ rõ một vai trò quan trọng khác của hội thảo: hội thảo có thể xúc tác hoặc tăng cường hợp tác giữa những người tham dự, từ đó có thể giúp các tổ chức đóng góp hiệu quả hơn vào các sáng kiến quản trị rừng. Chắc chắn, nhiều người tham dự hội thảo hiện đã có các quan hệ đối tác. Tuy nhiên, ngay cả trong các trường hợp như vậy, hội thảo được tổ chức để cung cấp một nền tảng cho các bên liên quan phản hồi và chia sẻ thông tin cũng đã giúp mở rộng hoặc củng cố quan hệ đối tác trong quá khứ lẫn hiện tại. Thứ hai, đối với các bên chưa từng có những mối quan hệ hợp tác trước đó, các hội thảo cung cấp những cơ hội để xây dựng những mối quan hệ mới.

ii. Khi các tổ chức hoạt động ở cùng một tỉnh, họ không có xu thế thường xuyên cộng tác với nhau. Kết quả này trái ngược với các lập luận hay kết quả nghiên cứu trước đây khi khẳng định rằng nếu hai tổ chức hoạt động trên địa bàn gần nhau về mặt địa lí, họ sẽ có nhiều điện kiện hơn trong việc phối hợp và hợp tác. Một trong những lí giải của các tổ chức tham gia nghiên cứu này là khi các tổ chức cùng thực hiện dự án trên cùng một địa bàn họ "cố gắng làm mình khác biệt và không dẫm chân lên những gì các tổ chức khác đã thành công làm". Ví dụ, một người phỏng vấn đại diện của một tổ chức giải thích rằng, "Chúng tôi cân bảo đảm dự án của chúng tôi khác biệt và không trùng lặp. Mặc dù chúng tôi và các tổ chức khác có thể làm việc trong cùng một tỉnh, nhưng chúng tôi sẽ không làm việc trong cùng một huyện, xã. Do các cách tiếp cận khác nhau, chúng tôi thấy không cân phải hợp tác". Một đại diện cơ quan chính quyền địa phương tham gia nghiên cứu cũng chia sẻ rằng, "Trong tỉnh tôi có rất nhiêu dự án và nhà tài trợ nhưng mỗi người lại áp dụng các tiêu chuẩn và cách tiếp cận khác nhau. Đó quả thực là một thách thức đối với chúng tôi. Ví dụ: chúng tôi phải làm việc với nhà tài trợ, những mỗi nhà tài trợ lại áp dụng các định nghĩa và cách vận hành chính sách liên quan đến đảm bảo an toàn an toàn xã hội khác nhau gây ra khó khăn cho tỉnh trong việc điêu phối các hoạt động này đông thời làm tăng chi phí thực hiện. Ngoài ra, mỗi chương trình lại áp dụng hỗ trợ thanh toán khác nhau, có dự án thì chi trả bằng hiện vật, có dự án lại chi trả băng tiên mặt gây ra nhiêu thắc mắc giữa cộng

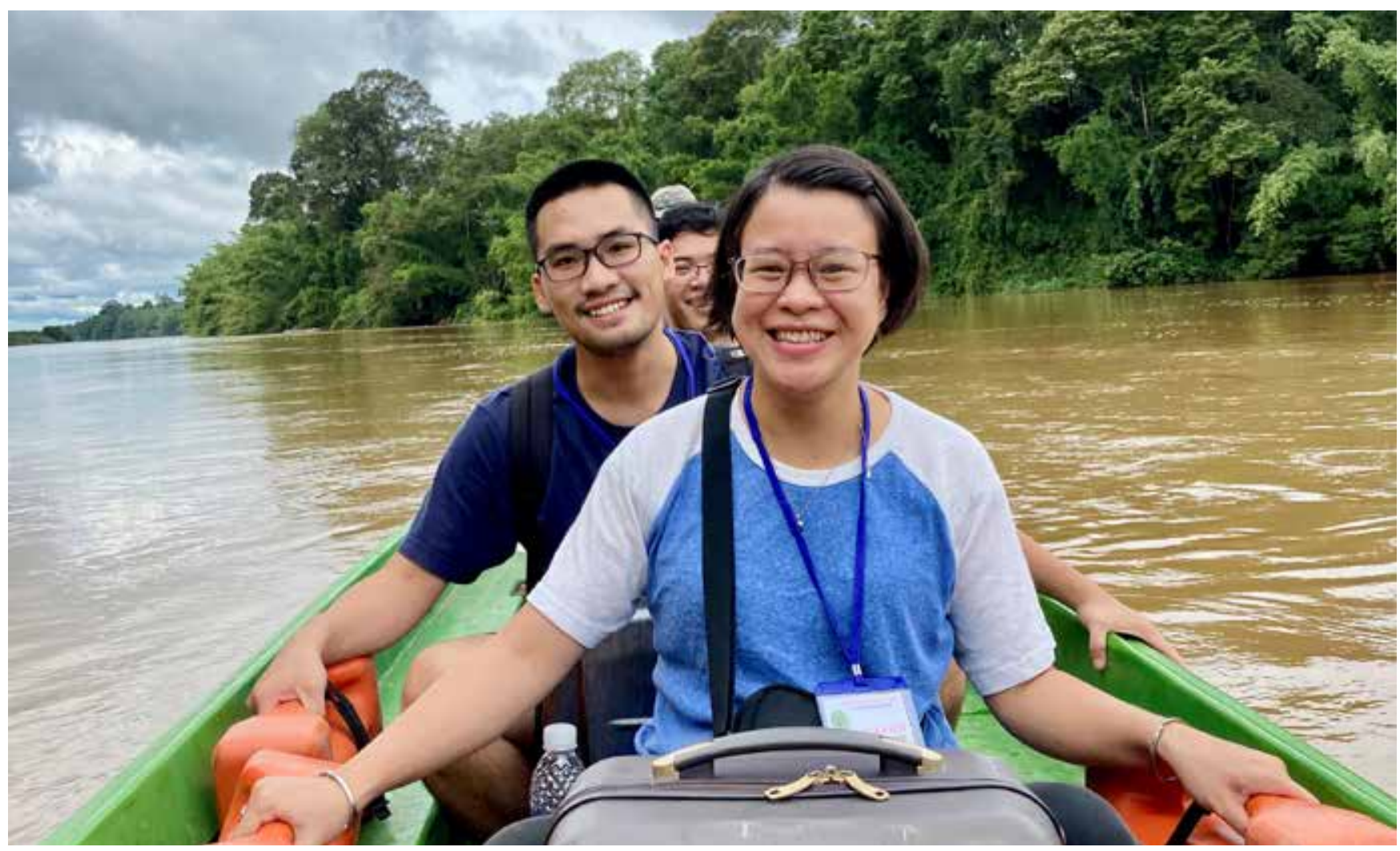

Nhóm nghiên cứu của CIFOR tới Vườn Quốc Gia Cát Tiên để tiến hành nghiên cứu đánh giá tác động của PFES.

Ảnh được chụp bởi Đào Thị Linh Chi 
đồng dân cư đặc biệt khi họ cho rằng có sự thiếu công băng và chúng tôi phải mất rất nhiều thời gian để giải thích cho họ". Kết quả này, nếu được xác nhận bằng phân tích đang được thực hiện, cho thấy thách thức tiềm tàng đối với quản lý điều phối các hoạt động liên quan đến PFES.

Hiện nay chúng tôi vẫn đang trong quá trình phân tích các tham số khác nhau. Trong thời gian tới, chúng tôi dự định tiến hành những nghiên cứu sâu hơn dựa trên phân tích kết hợp và tổng hợp số liệu về không gian địa lí, số liệu thực trạng (số lượng và chất lượng) của dịch vụ môi trường rừng như độ che phủ rừng (xin xem phần phân tích dưới đây), các mô hình phân tích tương quan giưa diện tích, chất lượng rừng với các yếu tố thủy văn. Ngoài ra, chúng tôi sẽ tiếp tục nghiên cứu sự tương tác giữa mạng lưới sinh thái (ví dụ hành lang đa dạng sinh học, mạng lưới thủy văn, sông ngòi) và mạng lưới xã hội và kết quả của sự tương tác này đối với kết quả bảo vệ và phát triển rừng. Đặc biệt, với kết quả nghiên cứu chỉ ra rằng các tổ chức hoạt động trên cùng địa bàn không có xu thế cộng tác và phối hợp với nhau, chúng tôi sẽ tiến hành các nghiên cứu sâu hơn xác định nguyên nhân và yếu tố có thể thúc đẩy sự hợp tác hiệu quả hơn.

\section{Tác động của PFES đối với thu nhập hộ gia đînh}

Mặc dù mục tiêu chính của PFES là tăng cường bảo vệ và phát triển rừng, song mục tiêu cải thiện sinh kế của người dân địa phương cũng được coi là ưu tiên quốc gia. Từ năm 2017, CIFOR đã thực hiện nghiên cứu so sánh trên cả nước để xác định đóng góp của PFES đối với thu nhập hộ gia đình tại Sơn La, Thừa Thiên Huế, Đắk Lắk và Vườn Quốc gia Cát Tiên. Bốn điểm nghiên cứu này đại diện cho các điều kiện khác nhau về các vùng sinh thái, phân loại rừng, người sử dụng và cung cấp dịch vụ môi trường rừng, doanh thu, mức chi trả, mô hình chia sẻ lợi ích. Tổng cộng, 2991 người đã tham gia vào nghiên cứu CIFOR này. Hình 1 giới thiệu tổng quan về đóng góp của PFES đối với tổng thu nhập hộ gia đình ở bốn điểm nghiên cứu này.

Tại bốn địa bàn nghiên cứu, 28\% hộ gia đình cho biết PFES đóng góp hơn 75\% thu nhập của họ, trong khi 27\% cho biết PFES chỉ đóng góp dưới 10\% thu nhập của họ. Các kết quả này về cơ bản khác nhau giữa các địa bàn nghiên cứu. Trong khi ở Thừa Thiên Huế và Sơn La, phần lớn các hộ gia đình cho biết PFES chỉ mang lại ít hơn 10\% thu nhập của họ (55\% số hộ được phỏng vấn ở Sơn La và 66\% ở Thừa Thiên Huế); ở Cát Tiên và Đắk Lắk, một số hộ được phỏng vấn (30\% ở Cát Tiên và $35 \%$ ở Đắk Lắk) cho rằng DVMTR đóng vai trò quan trọng, chiếm hơn 75\% thu nhập chung của họ. Điêu thú vị là mặc dù phần lớn các hộ gia đình ở Sơn La cho biết thu nhập từ DVMTR là rất thấp, có 37\% người phỏng vấn lại chia sẻ rằng PFES chiếm trên 75\% thu nhập hộ gia đình. Tác động của PFES đối với thu nhập của hộ gia đình phụ thuộc vào mức chi trả từ DVMTR, các phương án sinh kế sẵn có trong khu vực, diện tích rừng do hộ gia đình quản lý và việc PFES được quản lý thông qua hợp đông cá nhân với hộ gia đình hay hợp đông với chính quyền thôn bản. Tất cả các yếu tố này khác nhau đáng kể giữa các địa điểm nghiên cứu. Sự khác biệt giữa và trong các khu vực cho thấy những thách thức đối với chính quyền địa phương trong việc đảm bảo rằng những người mà PFES đóng góp dưới 10\% thu nhập của họ tích cực tham gia vào PFES, đặc biệt khi họ phải thực hiện các yêu cầu theo hợp đông giống như những người mà PFES đóng góp nhiêu hơn trong thu nhập của họ.

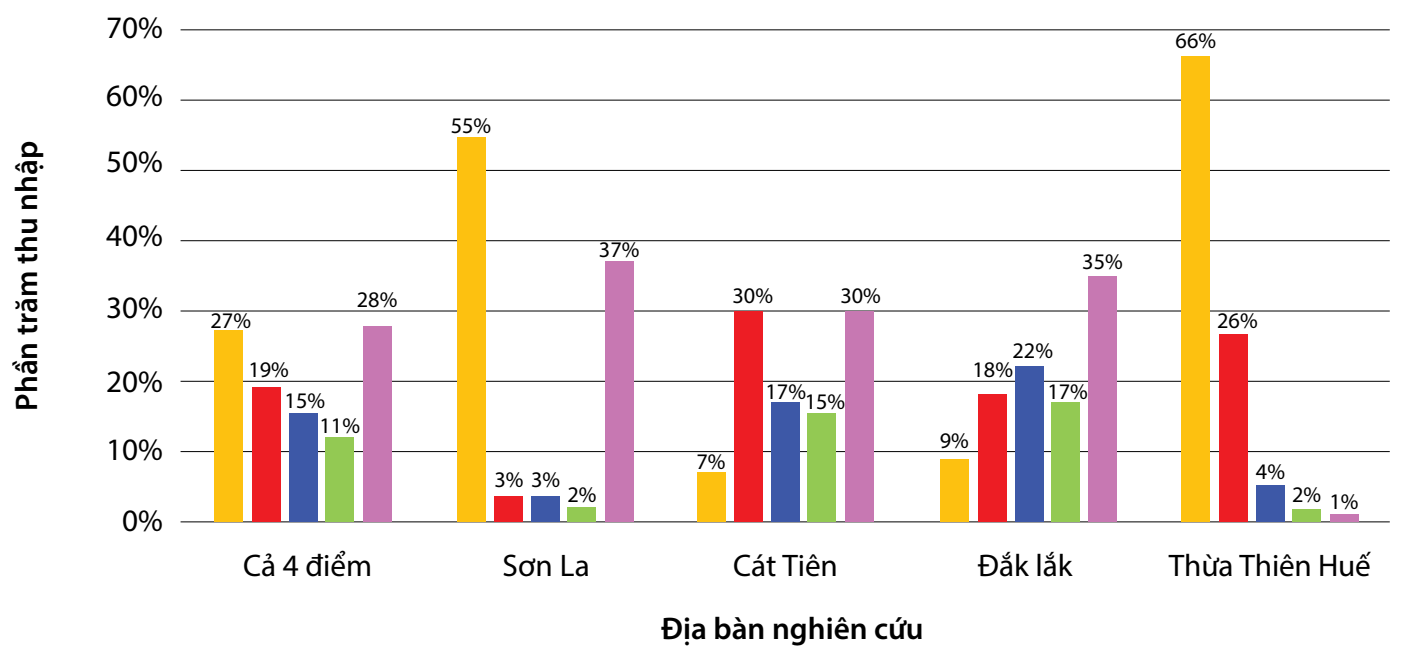

Hình 1. Thu nhập từ DVMTR tính theo tỷ lệ phần trăm trên tổng thu nhập hộ gia đình 


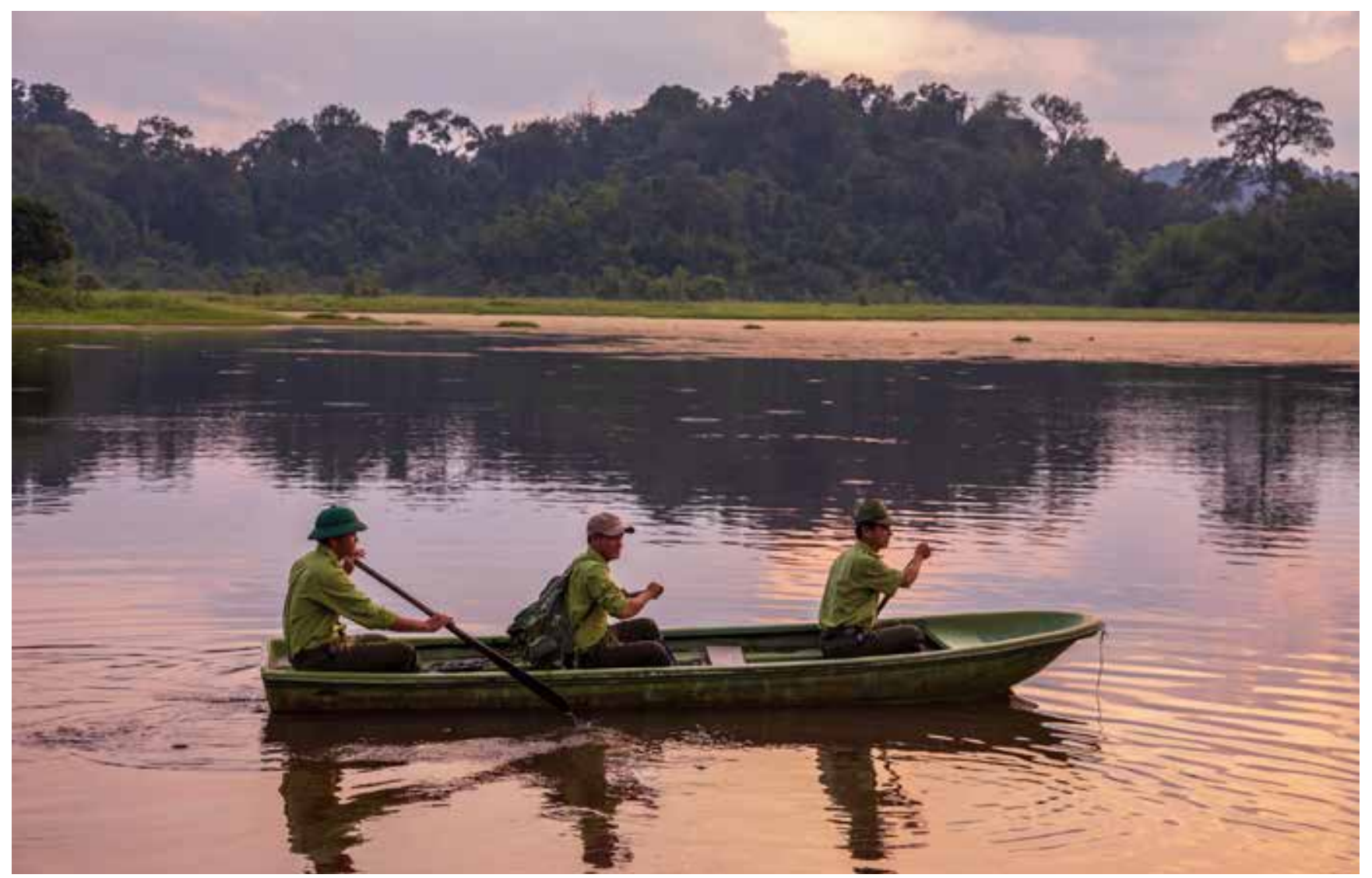

Cán bộ kiểm lâm Vườn Quốc Gia Cát Tiên

Ảnh được chụp bởi Binh Đặng/GIZ

\section{Tác động của PFES đối với việc giảm mất rừng}

Trong các đánh giá về hiệu quả PFES, một câu hỏi cốt lõi là liệu chương trình có thực sự làm giảm mất rừng hay không. Để đánh giá sơ bộ tác động của PFES đối với độ che phủ rừng, chúng tôi đã tiến hành phân tích thống kê sử dụng Bộ dữ liệu về biến đổi rừng toàn cầu của Hansen, bao gồm tình trạng mất rừng ở Việt Nam ở độ phân giải 30x30 mét (một pixel) từ năm 2000 đến năm 2018. Do quy mô của bộ dữ liệu này, phân tích sơ bộ dựa trên một mẫu ngẫu nhiên khoảng 2,5 triệu pixel có rừng vào năm 2000, xấp xỉ 1\% diện tích có rừng của Việt Nam trong năm đó.

Do chúng tôi đang nghiên cứu các sự kiện và đơn vị nghiên cứu độc lập (sự mất rừng của một pixel đã từng có rừng vào năm 2000), chúng tôi sử dụng hồi quy nguy cơ theo tỷ lệ Cox để lập mô hình các quá trình dẫn đến mất rừng. Hồi quy rủi ro theo tỷ lệ Cox mô hình hóa thời gian dự kiến cho đến khi một sự kiện xảy ra, trong trường hợp của chúng tôi là phá rừng. Mô hình cho phép chúng tôi thêm vào các biến độc lập có thể ảnh hưởng đến nguy cơ mất rừng và

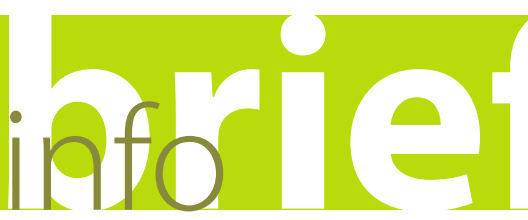




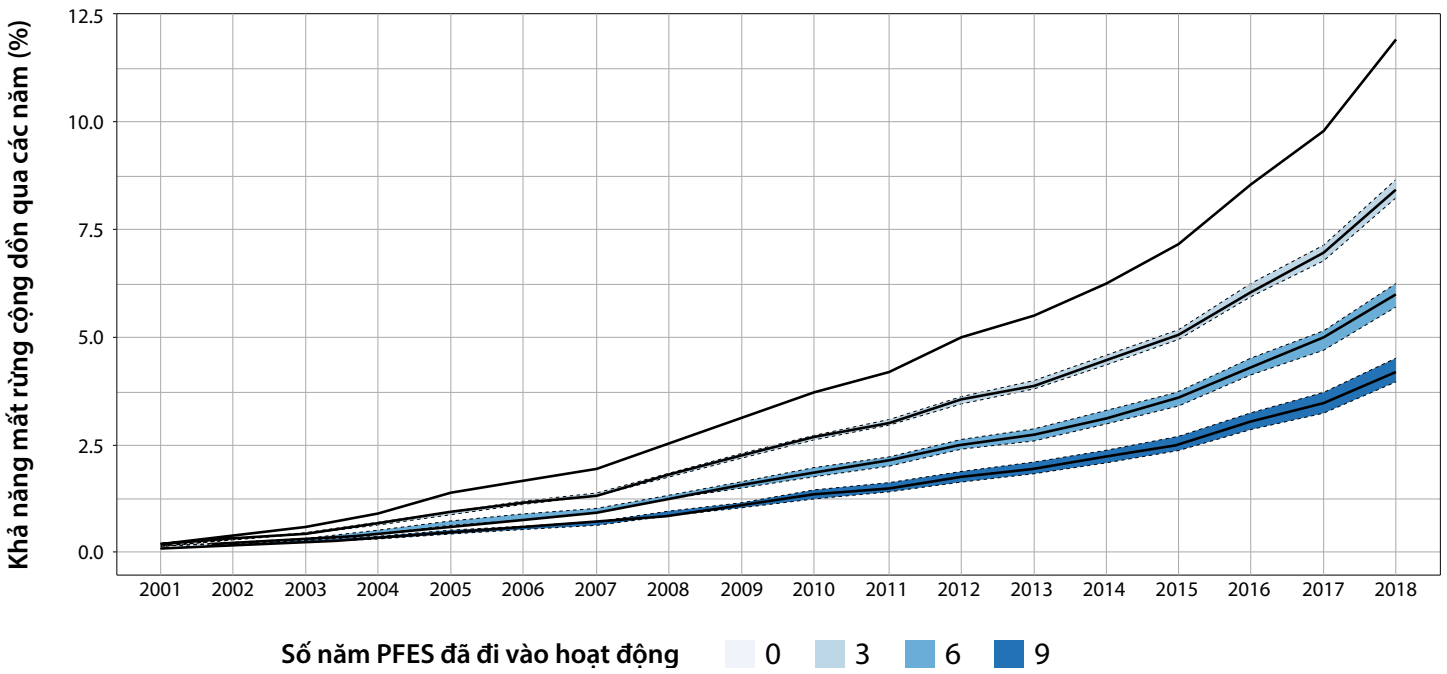

\section{Hình 2. Tình trạng mất rừng tích lũy được dự đoán theo thời gian thực hiện PFES, tất cả các biến khác được đặt bằng không}

Nguồn: Phân tích của các tác giả (2021). Các dải thể hiện khoảng tin cậy 99\% đối với rủi ro mất rừng tích lũy được dự đoán trong mỗi tình huống.

Hình 2 thể hiện rõ hơn về rủi ro mất rừng qua thời gian thực hiện PFES tại các điểm pixel mà chúng tôi nghiên cứu. Mặc dù đây là một mô hình dự đoán mô phỏng, nhưng mô hình có thể giúp chúng ta hiểu được mức độ ảnh hưởng của PFES đối với tình trạng mất rừng.

Mặc dù là giả thuyết, nhưng hình trên cho thấy hai thông điệp quan trọng từ kết quả chạy mô hình ở thời điểm hiện tại của chúng tôi. Thứ nhất, tỷ lệ mất rừng không có sự thay đổi lớn khi cộng dồn lại theo thời gian. Điều này có nghĩa là mặc dù PFES làm giảm tình trạng phá rừng chỉ trong thời gian ngắn, các tác động này sẽ dần dẫn đến tác động lớn hơn đối với công tác bảo tồn rừng trong tương lai dài hạn. Trong nhiều năm trở lại đây, đối với các tỉnh đã tham gia PFES trong một thập kỉ qua, tî lệ mất rừng chỉ bằng $1 / 3$ so với các tỉnh không thực hiện PFES. Thứ hai, điều quan trọng cần nhớ đó là chúng tôi cũng phân tích được các kết quả tương tự ngay cả khi so sánh giữa các pixel tại nhiều điểm địa lí khác nhau và bao gồm cả những tỉnh có rủi ro phá rừng cao.

Mặc dù những kết quả này cho thấy tiềm năng và tác động lớn của PFES trong việc giảm tî lệ mất rừng tại Việt Nam qua thời gian, nghiên cứu của chúng tôi còn một số hạn chế. Thứ nhất, với bộ dữ liệu về rừng của Hansen, chúng tôi chỉ xem xét các pixel có rừng vào năm 2000, có nghĩa là chúng tôi bị giới hạn ở các khu vực ít nhất rừng đã có độ tuổi trung bình. Các phát hiện của chúng tôi có thể khác đối với các khu vực đã được tái trồng rừng hoặc trồng rừng từ năm 2000. Thứ hai, từ thời điểm 2000, chúng tôi chỉ xem xét rủi ro mất rừng chứ không phải sự thay đổi tổng độ che phủ rừng, một vấn đề mà chúng tôi hy vọng sẽ khắc phục trong các phân tích trong tương lai. Cuối cùng, chúng tôi vẫn chưa kết hợp các phân tích về tác động của PFES đối với tî lệ mất rừng này với các phân tích mạng lưới quản trị lâm nghiệp để có thể hiểu rõ hơn về mối tương quan giữa hiệu quả quản trị mạng lưới lâm nghiệp và hiệu quả PFES.

\section{Thảo luận}

Bản tóm tắt này chỉ ra một số tác động quan trọng của chương trình PFES tại Việt Nam Nam đối với quản trị rừng, thu nhập hộ gia đinh và mất rừng. Mặc dù những phát hiện sơ bộ này cho thấy một số kết quả đầy hứa hẹn của PFES, chúng tôi cũng xác định một số thách thức cần được xem xét để cải thiện hiệu quả của chương trình PFES trong thời gian tới.

Trong thực tế, việc các hội thảo về PFES đã đóng vai trò như một chất xúc tác để thiết lập hoặc thúc đẩy sự hợp tác giữa các bên liên quan cho thấy PFES có thể có một số tác động xã hội tích cực cho các bên trong ngành lâm nghiệp. Tuy nhiên, việc các bên liên quan hoạt động trong cùng một tỉnh nhưng lại không có xu thế hợp tác thường xuyên với nhau chỉ ra những khó khăn mà chính quyền địa phương sẽ gặp phải trong việc phối hợp nhiều sáng kiến. Đặc biệt là khi các sáng kiến có cách tiếp cận không thống nhất sẽ tạo ra những mâu thuẫn xã hội khi người hưởng lợi không nhận được các cơ chế thực hiện và hưởng lợi giống nhau. Hơn nữa, sự phối hợp và cộng tác hạn chế giữa các bên trong cùng một tỉnh cũng dẫn tới các dự án không tiếp thu các bài học và kinh nghiệm sẵn có từ đó phát huy hoặc mở rộng phạm vi thực hiện, đem tới cho người hưởng lợi cả hỗ trợ tài chính và kỹ thuật với nhau. 


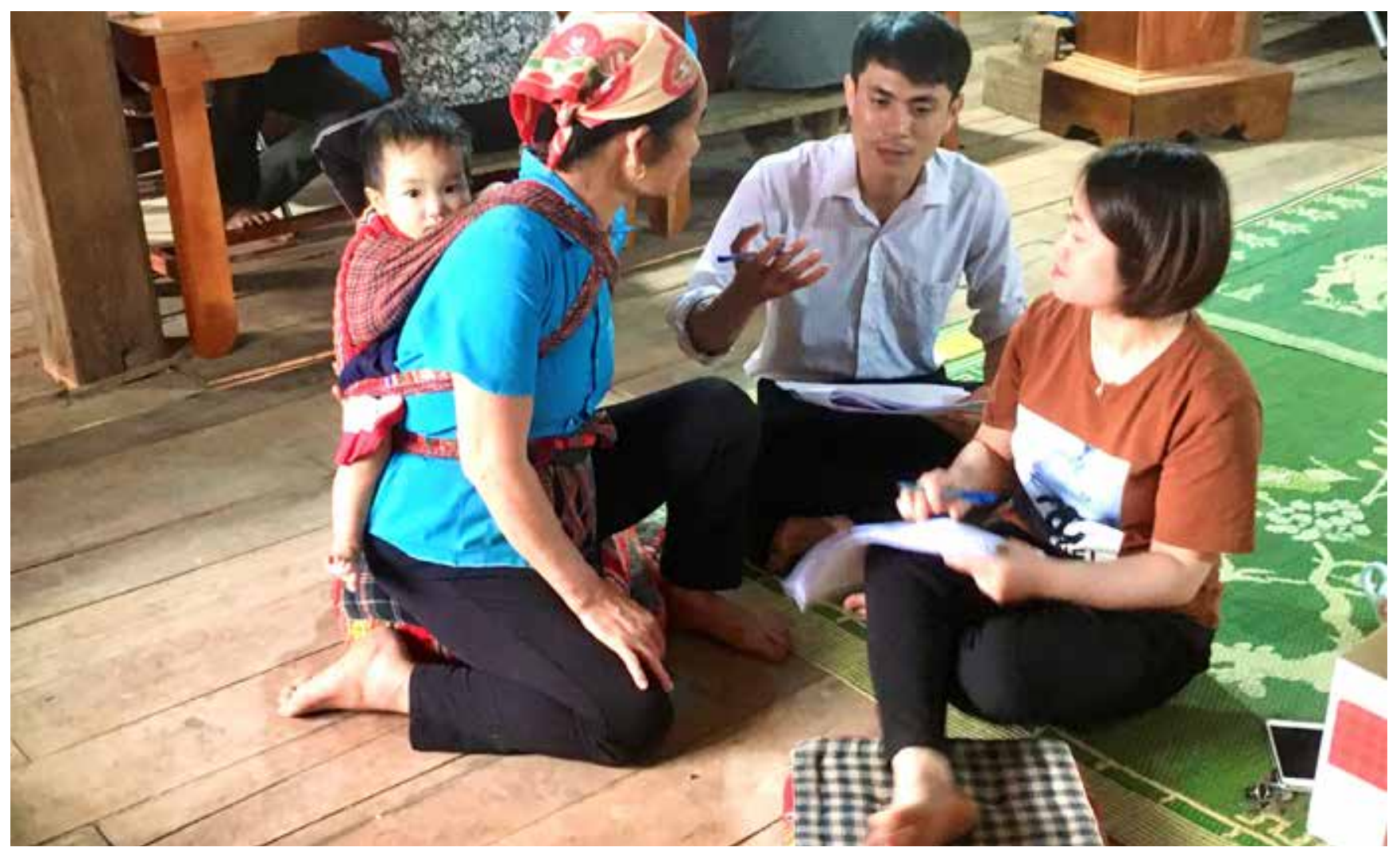

Thảo luận về tác động của PFES tại tỉnh Sơn La, Việt Nam.

Ảnh chụp bởi Pham Thu Thủy/CIFOR

Để giải quyết những thách thức này đòi hỏi sự hiểu biết đầy đủ hơn về cách các bên liên quan lựa chọn đối tác thực hiện dự án tiềm năng, trọng tâm cốt lõi của phân tích đầu tiên mà chúng tôi mô tả trong tóm tắt này. Hiểu được ai có khả năng và ai không có khả năng hợp tác (đánh giá năng lực) là bước đầu tiên quan trọng, nhưng hiểu được lý do tại sao chọn đối tác đó là bước quan trọng thứ 2. Ví dụ, các tổ chức có thể không hợp tác do thiếu thông tin, thiếu quan tâm, xung đột lợi ích và quyền lực, chênh lệch về năng lực tài chính hoặc năng lực khác, hoặc thiếu khung pháp lý. Thay vì đổ lỗi cho các tổ chức không hợp tác, chúng tôi tin rằng chúng ta cần nghiên cứu và hỗ trợ tăng cường vai trò vốn đã quan trọng của chính quyên trung ương, chính quyền cấp tỉnh và các tài trợ trong việc thúc đẩy sự hợp tác này một cách hiệu quả hơn.

Trong thực tế, không chỉ các tổ chức dự án hạn chế phối hợp và hợp tác với nhau mà thách thức về việc hợp tác cũng được nhận thấy trong liên kết giữa các cơ quan chính phủ. Ví dụ, nhiều dự án được chính quyền trung ương phê duyệt mà không tham vấn chính quyền cấp tỉnh. Một câu hỏi quan trọng khác là tính đại diện của các bên liên quan (ví dụ, các cơ quan chính phủ, cộng đông địa phương, CSO và các nhà quản lý dự án, một số những nhóm khác) trong các hội thảo và mức độ hợp tác trải dài giữa các nhóm này với nhau. Nếu một dự án không phối hợp với các tổ chức xã hội dân sự và cộng đồng địa phương trong việc thực hiện PFES, sẽ rất khó để dự án này mang lại các kết quả bền vững về môi trường và xã hội. Đánh giá tính đại diện và sự hợp tác đa ngành giữa những bên tham gia hội thảo là trọng tâm cốt lõi của những phân tích tiếp theo.

Sự khác biệt mà chúng tôi quan sát thấy trong đóng góp của DVMTR đối với thu nhập hộ gia đình ở các địa điểm nghiên cứu cũng cho thấy chính phủ cần có những hỗ trợ cụ thể cho những người có ít động lực tham gia vào PFES do lợi ích họ nhận được hạn chế (ví dụ, các nhóm mà PFES đóng góp ít hơn 10\% thu nhập hộ gia đình). Trong nhiều trường hợp (như Sơn La và Thừa Thiên Huế cho thấy), các nhóm này hiện đang là đối tượng hưởng lợi chính của PFES và có thể đóng vai trò quan trọng đối với sự thành công liên tục của PFES. Tuy nhiên, việc tăng mức chi trả DVMTR hay tăng đóng góp từ PFES vào tổng thu nhập của họ không dễ dàng, khi họ chỉ quản lí một diện tích rừng nhỏ trong khi các lựa chọn sinh kế còn hạn chế. Tuy nhiên, sự kết hợp giữa chi trả bằng hiện vật hiện vật (ví dụ, hỗ trợ kỹ thuật, trao đổi thông tin) với chi trả bằng tài chính có thể tạo ra động lực mạnh mẽ hơn cho các chủ thể này tham gia vào PFES.

Những phát hiện của chúng tôi về tác động của PFES trong việc giảm tình trạng mất rừng cũng nhấn mạnh tầm quan trọng của các sáng kiến bảo tồn trong việc cung cấp hỗ trợ tài chính để khuyến khích cho các chủ rừng bảo vệ rừng tốt hơn. Tuy nhiên, như chúng tôi đã đề cập ở trên, các tác động ước tính của PFES có thể sẽ khác nhau tùy thuộc vào nguồn dữ liệu 
và phương pháp được sử dụng. Phân tích trên cần được bổ sung với các bộ dữ liệu và kỹ thuật mô hình hóa khác nhau để khẳng định một cách vững chắc những phát hiện này. Điều này cũng nhấn mạnh về tầm quan trọng của việc xây dựng và đưa vào thực hiện một hệ thống giám sát, theo dõi, báo cáo và thẩm định toàn diện và minh bạch, có sự tham gia của các bên có liên quan để đo lường các tác động của PFES và báo cáo những kết quả này cho công chúng.

Hơn nữa, các tác động của PFES không thể được đánh giá một cách đơn lẻ mà phải được xem xét trong bối cảnh các chính sách hiện có, điều kiện môi trường của địa phương và các động lực kinh tế xã hội của địa phương. Trong khi bản tóm tắt này thảo luận riêng về tác động của PFES đối với quản trị rừng, sinh kế người dân và sự mất rừng, sự tương tác đa chiều và tổng hợp giữa các yếu tố này có thể đưa ra một bức tranh rất khác. Việc phân tích dữ liệu tổng hợp về sự hợp tác của các bên liên quan, lợi ích tài chính đem lại từ PFES và sự thay đổi rừng ở các điểm nghiên cứu về PFES có thể giúp các bên liên quan xác định các yếu tố ảnh hưởng đến tác động của PFES và cung cấp thông tin đánh giá toàn diện hơn về tác động của PFES cũng như làm thế nào để nâng cao kết quả thực hiện chính sách này.

\section{Lời cảm ơn}

Chúng tôi trân trọng cảm ơn chương trình Quan hệ đối tác để nâng cao gắn kết trong nghiên cứu (PEER), được tài trợ bởi Cơ quan Phát triển Quốc tế Hoa Kỳ (USAID) và Cơ quan Hợp tác Phát triển Na-Uy (NORAD) vì đã cung cấp hỗ trợ tài chính cho báo cáo tóm tắt này. Chúng tôi cũng gửi lời cảm ơn đặc biệt tới Chương trình Rừng và Đồng bằng Việt Nam và Tổ chức Hợp tác Kỹ thuật Đức (GIZ) vì đã hỗ trợ chúng tôi trong quá trình thu thập dữ liệu.

\section{Tài liệu tham khảo}

Hansen, M. C., Potapov, P. V., Moore, R., Hancher, M.,

Turubanova, S. A., Tyukavina, A., Thau, D., Stehman, S. V., Goetz, S. J., Loveland, T. R., Kommareddy, A., Egorov, A., Chini, L., Justice, C. O., \& Townshend, J. R. G. (2013). Các bản đồ độ phân giải cao về sự thay đổi độ che phủ rừng trong thế kỉ 21. Science 342(6160): 850-853.

Phạm T, Đào TLC, Hoàng TL, Ngô HC, Trần NMH, Nguyễn DT. 2020. Các tác động PFES tại Việt Nam. Bài trình bày tại Hội thảo Quốc Gia- 10 năm thực hiện PFES tại Việt Nam, Hà Nội, Việt Nam.

\begin{tabular}{|c|c|c|}
\hline (1) & $\begin{array}{l}\text { RESEARCH } \\
\text { PROGRAM ON } \\
\text { Forests, Trees and } \\
\text { Agroforestry }\end{array}$ & $\begin{array}{l}\text { Chương trình nghiên cứu CGIAR về Rừng, Cây và Nông lâm kết hợp (FTA) là chương trình nghiên cứu } \\
\text { phát triển lớn nhất trên toàn cầu nhằm nâng cao vai trò của rừng, cây, và nông lâm kết hợp trong phát } \\
\text { triển bền vững, đảm bảo an ninh lương thực và thích ứng và giảm thiểu biến đổi khí hậu. CIFOR điêuu } \\
\text { phối FTA và hợp tác với ICRAF, Liên minh đa dạng sinh học quốc tế, CIAT, CATIE, CIRAD, INBAR và TBI. }\end{array}$ \\
\hline & & Các nghiên cứu của FTA cũng nhận được sự tài trợ của Quỹ Ủy thác CGIAR: cgiar.org/funders/ \\
\hline
\end{tabular}
nghiên cứu sáng tạo, nâng cao năng lực của các bên đối tác, tích cực tham gia đối thoại với các bên liên quan để hỗ trợ định hình chính sách và thực tiễn tác động tới rừng và con người. CIFOR là tổ chức nghiên cứu thuộc liên minh CGIAR và chủ trì các chương trình nghiên cứu của CGIAR về Rừng, Cây gỗ và Nông lâm kết hợp (FTA). Trụ sở chính của CIFOR đặt tại 